\title{
CEREBRAL FAT EMBOLISM WITH RECOVERY: AND INVOLVEMENT OF THE CENTRAL RETINAL ARTERY
}

BY

\section{J. JAMESON EvANS}

BIRMINGHAM

THE condition of cerebral fat embolism is considered to be fatal in the majority of cases and recovery is rare. Indeed the clinical syndrome of cerebral fat embolism is not as universally recognised as might be expected in an age in which an increased number of such cases is to be expected as a result of the mounting toll of the roads. Corlette (1925) has given a clear description of the characteristics and also records one of the few instances of recovery. He mentions the association of delirium with a pulse of low tension, coming on some hours after the initial injury, passing to coma with hyperpyrexia, the frequency of incontinence of urine and faeces, and the appearance of a petechial eruption in the majority of cases in from twelve hours to three days. This latter sign and the sudden passing from consciousness to coma without the accompaniment of cerebral symptoms are pathognomonic. Corlette's case which recovered showed symptoms of cerebral fat embolism some thirty-six hours after the accident and had recovered in three days. Unfortunately there is no note of any examination of the fundus oculi. Dahl (1924) records three cases of recovery. Benestadt '(1911) also reported three cases which recovered, but none of these reached the stage of coma, although all showed some degree of delirium. Some of the cases reported have, however, shown no degree of hyperpyrexia, while those of Benestadt showed only slight rise of temperature. In these cases petechiae were observed on the third day. This paper contains no note of observations of the fundus oculi nor of any visual disturbances.

The present case is notable for the absence of initial head injuries and for the speediness of recovery, as well as for involvement of the retinal arteries in both eyes. The details of this case may be summarised as follows, from notes supplied by Mr. W. H. George, Dudley Road Hospital, the Surgeon in charge of the case, whose clinical acumen led to the diagnosis of this case.

F.R., aged 23 years, suftered a road accident on June 21, 1938. On June 22, he was admitted to hospital where his condition was briefly this:-Patient was drowsy but conscious; he answered questions intelligently but had no recollection of the accident. There were numerous bruises and lacerations of the right arm, 
shoulder and leg. There was a fracture of the right tibia and fibula some four inches above the ankle, with considerable displacement, a star-shaped fracture of the right patella, and an oblique fracture of the right ulna extending to the elbow joint.

These fractures were dealt with the same day under open ether anaesthesia, the leg being manipulated and set up in plaster.

On June 23 the patient became very drowsy and this was more marked on the following day, when he reached a condition of surly sub-coma, and became incontinent of urine. A petechial rash appeared on the chest and neck and there was transient squint of the left eye. Lumbar puncture gave a clear fluid under normal pressure, the urine contained fat globules but was otherwise clear, the blood showed a high percentage of fatty acids.

On June 25 the patient was still very drowsy and incontinent but could be made to answer questions. He was unable to recognise his relatives at this time. The appearances of the fundi on this day were of interest as showing the involvement of the retina in the process of fat embolism. The external appearance of the eyes was normal. The pupils reacted to light and at no time was there any complaint of disturbance or defect of vision. The tension was normal in each eye and the media were clear. The ophthalmoscopic picture was exceptionally striking. There was diffuse oedema of the retinae over the whole of the posterior poles, suggestive of shallow retinal detachment, with the retinal vessels standing out prominently, but without any material variation of size, calibre, or tortuosity, and no segmentation of the blood columns. Retinal oedema was definitely more pronounced in the macular area, where also three slightly crescentic areas of intensified pallor were noticeable: one at least of these whiter areas appeared to be in the deeper layers of the retina. (Plate).

In the right eye, well outside and below the macula and towards the periphery, there were two large sub-hyaloid haemorrhages, each more than a disc diameter in size, under one of which a vein could be seen to pass. In the left eye a similar but smaller haemorrhage was seen near the periphery on the nasal side.

On June 29 the patient's mental condition began to improve, and he became continent of urine.

On July 6 he was so recovered as to be reading a book with interest. On this day ophthalmoscopic examination showed that the oedema of the retinae was much less, but there still remained haze, pallor and shot-silk appearance in the central area. The sub-hyaloid haemorrhages were showing early reabsorption.

On August 11 vision in each eye was 6/6 without glasses. There was still a small remnant of the larger of the sub-hyaloid haemorrhages to the outer side and below the macula but the smaller had 
become completely absorbed. In all other respects the appearance of both fundi was absolutely normal.

\section{REFERENCES}

Corlette, C. E.-Med. Jl. of Australia, Vol. I, p. 229, March 7, 1925.

BenEstadT, G.-Deutsch. Zeitschr. f. Chirurg.. Vol. CXII, pp. 144-205, 1911; Abstract, Zentralbl. f. Chirurg., Vol. XXXIX, p. 18, 1912.

Godlee, R. D. and Willia.Ms, G.-Lancet, Vol. I, p. 1062, April 22, 1911.

OEHLER.-Beiträge zur klin Chirurg., Bd. 3, Vol. LXV, p. 1, 1909.

DAнL, R. J.-Tidskrift f. $d$. Norske-Laege-Forenig, p. 610, July 1, 1924 ; Abstract, Brit. Med. Jl., Epitome 231, September 27, 1924.

\section{ANNOTATION}

\section{The Man and the Machine}

It was natural in the early days of aviation that more attention should be paid to the newly invented and rapidly developing machine than to the man who worked it. In a paper on "Pilot Fitness" published in this number, Drs. Ferree and Rand lay great stress on the neglect of the human factor in aviation. It is probable that the indictment is true of the Air Forces of most nations, but it is certain that this factor early received attention in England. The R.F.C. was fortunate in having for it first Director General of Medical Services, General Sir Mathew Fell, and for its second, Air Vice-Marshal Sir David Munroe, who gathered around them an enthusiastic band of men, of whom Group Captain Flack was a specially distinguished pioneer in many branches of medicine as applied to the specific problems of aviation. An advisory medical committee was also instituted, but it must be admitted that it was not so constituted as to be ideal for a service which demanded research into the many new and difficult problems which flying men had to face. The R.A.F. from an early date had a very elaborate and admirably constituted committee on Aeronautical Research. In due course it was recognized that the human factor was as important as the machine, and a Personnel Research Committee was set up to deal with the physiological, psychological and pathological factors involved in flying. The problems to which Drs. Ferree and Rand refer have therefore by no means been neglected in England, and possibly some of the success of our aviators since the War began is to be attributed to this fact. 